\title{
Meningitis Tuberculous with Miliary Tuberculosis and Thoracic Vertebrae Level 11-12 Tumor showing Neurofibroma Patterns: A Case Report
}

\author{
Andi Wijayanto ${ }^{* 1}$,Nunuk Sri Muktiati ${ }^{1}$, Farhad Bal'afif ${ }^{2}$, Sri Budhi Rianawati ${ }^{3}$ \\ ${ }^{1}$ Pulmonology and Respiratory., Saiful Anwar Hospital-Brawijaya University, Jaksa Agung Suprapto 2, Malang, 65112, Indonesia \\ ${ }^{2}$ Neurosurgery Dept., Saiful Anwar Hospital-Brawijaya University, Jaksa Agung Suprapto 2, Malang, 65112, Indonesia \\ ${ }^{3}$ Neurology Dept., Saiful Anwar Hospital-Brawijaya University, Jaksa Agung Suprapto 2, Malang, 65112, Indonesia
}

\begin{abstract}
Background: Tuberculosis is an infectious disease that develop from systemic infection caused by bacterium Mycobacterium tuberculosis complex. Generally, M.tuberculosis spread from one person to another through nuclear droplet air transmission. Although $\mathrm{TB}$ has a lower transmission rate compared to another infectious disease, TB still become a global health problem. It is estimated that approximately one third of the world's population is infected by tuberculosis. Every year it is estimated that there are nine million new cases and close to two million death cases caused by tuberculosis.

Case: A 24-year-old female was admitted to the hospital complaining of could not move both of her legs and could not urinate. One month before admission, she was diagnosed with meningitis TB; miliary TB; and meningioma at thoracic vertebrae T11-12 based on physical examination, laboratory examination, Chest X-Ray, Head CT Scan without contrast, and thoracolumbal MRI. When admitted to the hospital, the patient already treated with Fixed Dose Combination of antituberculosis Drugs first category for one and a half month from Turen Primary Healthcare. Then the patient underwent bronchoscopy examination. The result of the anatomical pathology examination showed class two. Then the patient underwent a laminectomy surgery and tumor excision at thoracic vertebrae T11-12. The result of postoperative Anatomical Pathology examination showed a neurofibroma pattern. After surgery, the Physical Medicine and Rehabilitation Department placed thoracic lumbosacral orthoses (TLSO) to the patient. Postoperative evaluation up to three months showed that the patient's general condition was quite good but still cannot move both of her legs and cannot urinate.
\end{abstract}

MRJ 2019; 1(1):2-10

Keywords: tuberculosis, meningioma, laminectomy; thoracic lumbosacral orthoses

\section{Introduction}

Tuberculosis is an infectious disease that develop from systemic infection caused by bacterium Mycobacterium tuberculosis complex. Generally, M.tuberculosis spread from one person to another through nuclear droplet air transmission. Although TB has a lower transmission rate compared to another infectious disease, TB still become a global health problem. It is estimated that approximately one third of the world's population is infected by tuberculosis.

${ }^{*}$ Corresponding author:

Andi Wijayanto (andi_juventini@yahoo.co.id)

Pulmonology and Respiratory Dept., Saiful Anwar Hospital-Brawijaya University, Jaksa Agung Suprapto 2, Malang, 65112 , Indonesia 
Tuberculosis is the main cause of preventable mortality and morbidity in the world. Every year it is estimated that there are nine million new cases and close to two million death cases caused by tuberculosis. Tuberculosis mainly attacks the lung and if there is spread through the blood, its causing extrapulmonary $\mathrm{TB}^{1,2,3,4,5,6}$. Miliary $\mathrm{TB}$ is a pathological name that describes millet granulomas of seed size (1-2 mm) in many organs that affected by tuberculosis bacilli. The manifestation spectrum of miliary TB still confused health experts and its diagnosis and treatment are a challenge for clinicians. Although the effective treatment is available, the mortality rate is still high. Miliary TB diagnosed with diffuse miliary infiltrate shown in chest $\mathrm{x}$-ray examination or High Resolution Computed Tomography (HRCT) scan or military tubercle at the multiple organ in laparoscopy, open surgery, or autopsy ${ }^{6,7}$. Subacute/chronic meningitis is a meningitis which the onset of the disease is more than four weeks, can also be around 2-8 weeks. The most frequent causes of subacute/chronic meningitis are Mycobacterium tuberculosis. The onset of the disease is veiled and progressive. Meningitis TB is difficult to diagnose and treat, there's non-specific clinical symptoms, the conventional bacteriology that is widely used is not sensitive, and diagnostic assessment methods are not completed yet ${ }^{8}$. Neurofibroma is a tumor that consist of nerve tissue and is benign. Neurofibroma is a benign tumor in the nerve covering membrane in the peripheral nervous system. Neurofibroma arised from nonmyelinated Schwann. The symptoms can be varied from physical disfiguration, pain, and cognitive disability ${ }^{9}$. In this paper, we present a case of patient that was diagnosed with meningitis TB; miliary TB; thoracic vertebrae T11-12 tumor showed a neurofibroma patterns.

\section{Case}

A 24-year-old female was admitted to the hospital at $21^{\text {st }}$ March 2013 complaining of could not move both of her legs and could not urinate since one month ago. The patient also complained that she felt right chest pain but did not radiating and did not penetrating to the back. The patient also complaining about mild febrile since three months ago. She felt decrease of appetite and weight loss about seven kilograms in four months. From the physical examination, there's no abnormality in head, neck, and thorax. 
Both of the lower extremities was atrophy. There was decrease of tonus in the motoric function examination. In the sensory function examination, there was hypesthesia at $11^{\text {th }}$ thoracic vertebrae level. In the autonomic nervous system examination, there was urinary retention. In the neurologic examination at L2, L3, L4, L5, S1 the score was zero. From the laboratory blood examination showed an increased in leucocyte levels and erythrocyte sedimentation rate. It is also found a decrease in sodium and potassium levels. The laboratory finding shown in Table 1.

Table 1. Laboratory Finding

\begin{tabular}{|c|c|}
\hline Component & Result \\
\hline Leucocyte & $12.540 / \mu l$ \\
\hline Hemoglobin & $12,10 \mathrm{gr} / \mathrm{dl}$ \\
\hline $\mathrm{PCV}$ & $34,60 \%$ \\
\hline Thrombocyte & $417.000 / \mu 1$ \\
\hline ESR & $86 \mathrm{~mm} / \mathrm{h}$ \\
\hline RBG & $126 \mathrm{mg} / \mathrm{dL}$ \\
\hline Sodium & $129 \mathrm{~g} / \mathrm{dl}$ \\
\hline Potassium & $3,56 \mathrm{mmol} / \mathrm{L}$ \\
\hline Chloride & $104 \mathrm{mmol} / \mathrm{L}$ \\
\hline Albumin & $3,98 \mathrm{~g} / \mathrm{dl}$ \\
\hline
\end{tabular}

From the urinalysis, showed that there was bacteriuria. The urinalysis results shown in Table 2.
Table 2. Urinalysis Results

$\begin{array}{ll}\text { Component } & \text { Results } \\ \text { Specific Gravity } & 1,015 \\ \text { Ph } & 6,0 \\ \text { Leucocyte } & 3+ \\ \text { Protein } & 1+ \\ \text { Ketone } & 1+ \\ \text { Erythrocyte } & 3+ \\ \text { 40x Magnification } & \text { Erythrocyte: } 9,1 \\ & \text { Leucocyte: } \\ & 389,1 \\ \text { Bacteria } & 5562,7 \times 103\end{array}$

Examed at 21st March 2013

From the cerebrospinal fluid examination, showed a $100 \%$ Mononuclear cells. There's also positive Nonne test and positive Pandy test. The cerebrospinal fluid examination results shown in Table 3.

Table 3. Cerebrospinal Fluid Analysist

Macroscopic

- Color: Reddish Yellow

- Clot: -

- Clarity: Cloudy

Chemical

- Protein: 1404,9 mg/Dl

- Glucose: 46 mg/Dl

- LDH: $249 \mathrm{IU} / \mathrm{L}$

Microscopic

- Erythrocyte count: $7600 / \square \mathrm{L}$

- Leucocyte count: $50 / \square \mathrm{L}$

- PMN cells: -

- MN cells: $100 \%$ 
From the chest $\mathrm{x}$-ray examination before treated with antituberculosis drugs first category, showed diffuse miliary infiltrate in all of right and left lung field $\left(25^{\text {th }}\right.$ January 2013). From the CXR examination after intensive phase of antituberculosis drugs first category treatment (22 ${ }^{\text {nd }}$ March 2013),

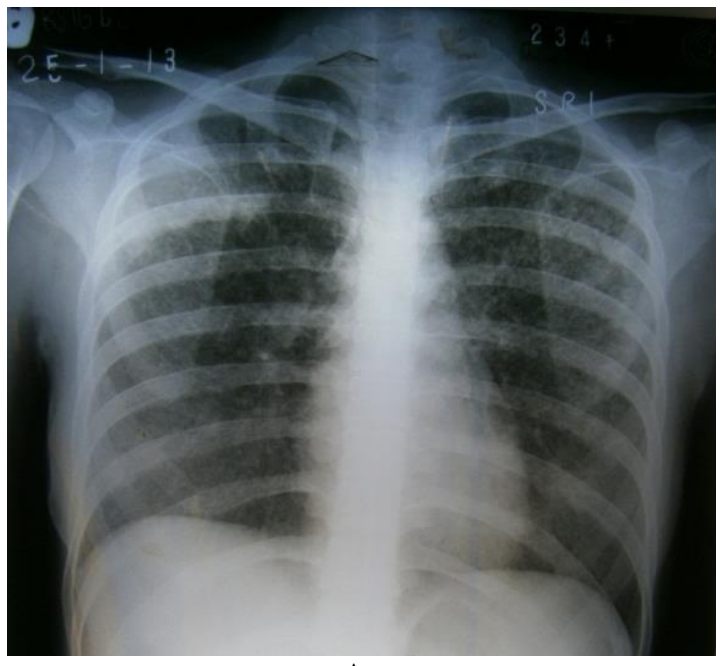

A

25th January 2013 showed that there was improvement from the fist radiographic examination. The chest $\mathrm{x}$-ray examination results shown in Figure 1. From Figure 2 the lumbosacral MRI examination a pattern of meningioma showed with a mass size of $7 \times 20 \mathrm{~mm}$ surrounding the central

canal

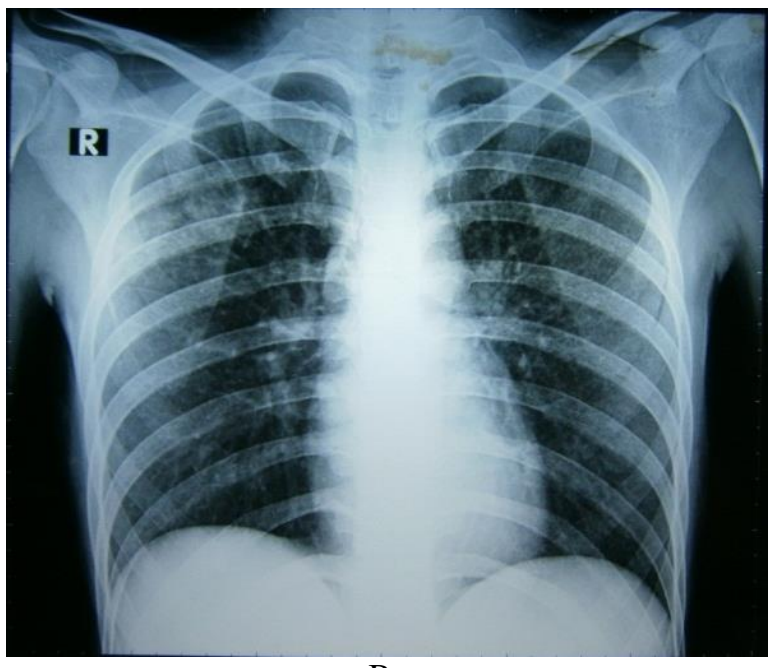

B

22nd March 2013

Figure 1. First category Antituberculosis Drugs showing improvement on Chest X-Ray Examination Before Treated with (A) comparing with After Intensive Phase (B)

Figure 2. lumbosacral MRI showed a pattern of meningioma at thoracic vertebrae T11-12 level From the spirometry examination with semifowler position, showed that there

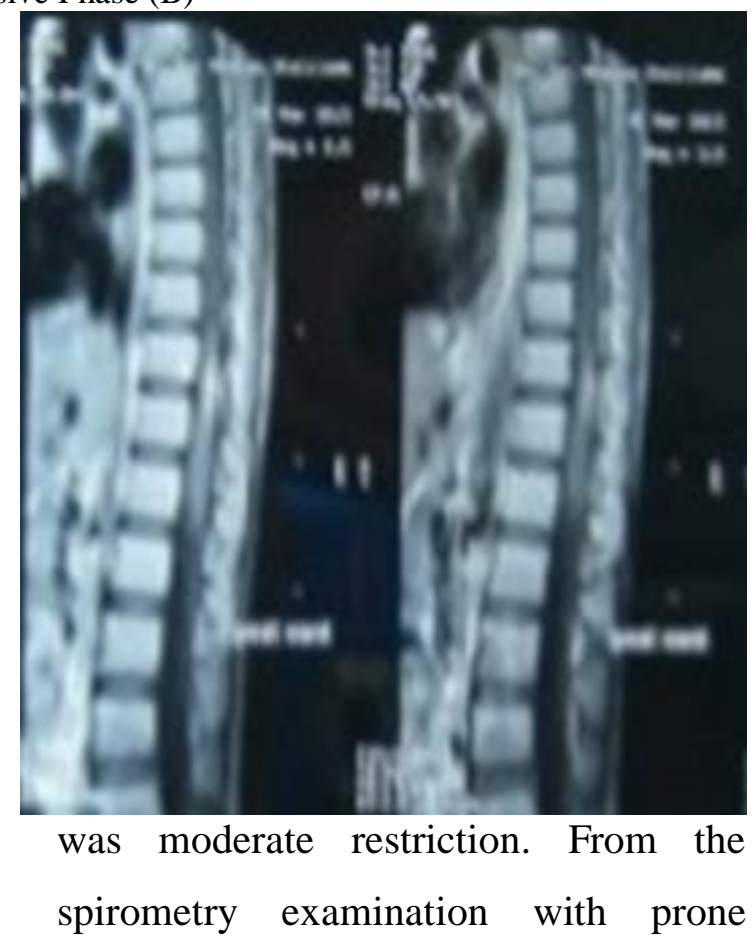

vol 1 (1) page 5 
position (to assess the risk for surgery), showed that there was moderate restriction. There is no difference significant between semi Fowler and prone position. Based on data above, the patient was diagnosed with miliary TB on Antituberculosis Drugs First Category and there was a pattern of thoracic vertebrae T11-12 tumor with meningioma pattern. The patient was treated with Fixed Dose Combination of
Antituberculosis Drugs with 2RHZE//4R3H3 regiment, with two Fixed Dose Combination tablets every day for two months (intensive phase) and two Fixed Dose Combination tablets three times in a week for four months (continuation phase). Subsequently, the patient was scheduled to laminectomy and tumor excision surgery at $30^{\text {th }}$ April 2013.
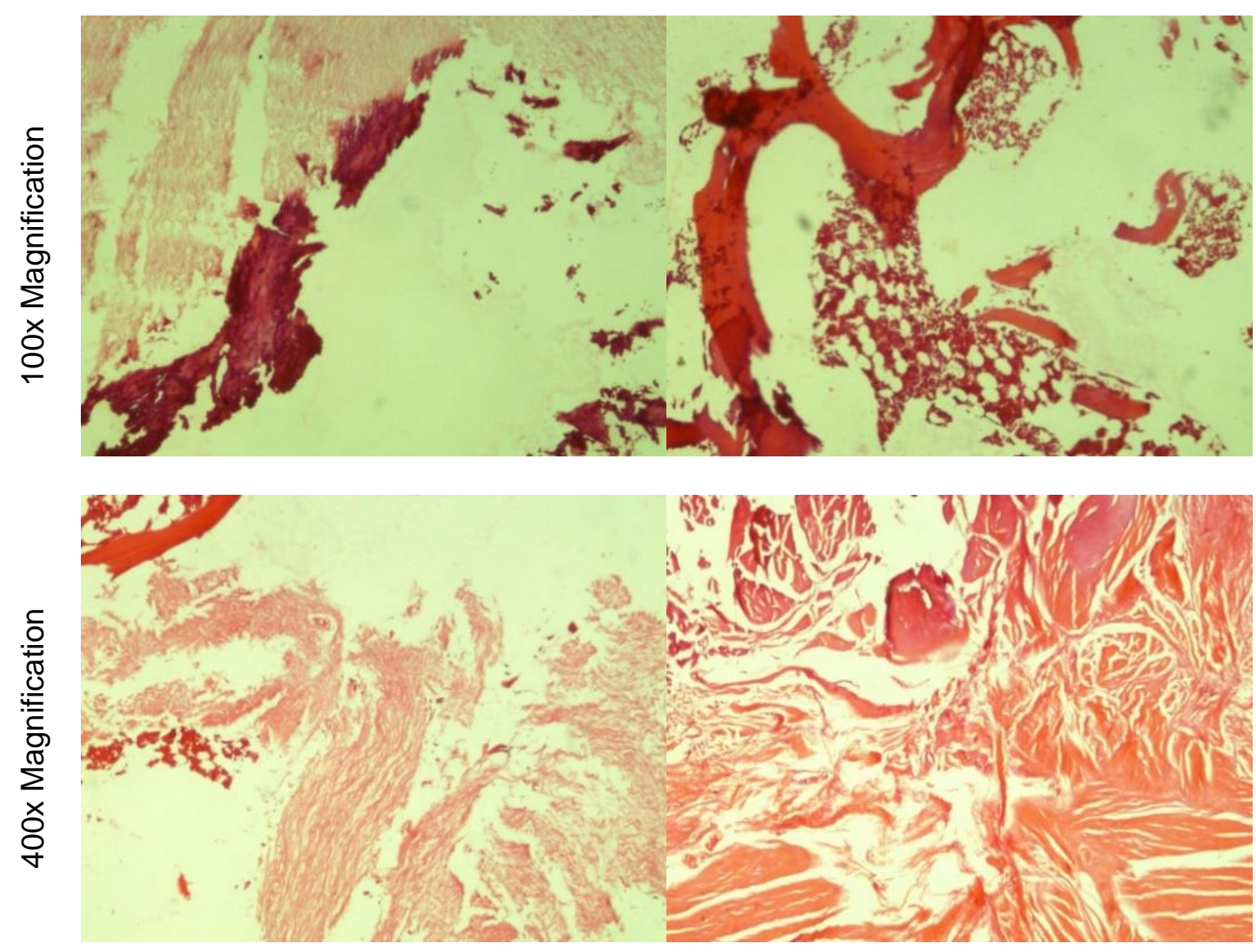

Figure 3. Postoperative Histopathology Examination Results. A neurofibroma patterns findings. Sample post laminectomy and tumor excision results showed. 
The patient was undergone laminectomy and tumor excision surgery at $30^{\text {th }}$ April 2013. The patient was diagnosed with Thoracic intramedullar tumor at thoracic vertebrae T11-12 level. The tumor was examined macroscopic and microscopically. The results of macroscopic examination showed a mass consists of bone tissue with size of $6.5 \times 1.5 \times 0.5 \mathrm{~cm}^{3}$, and another small tissue about $6 \mathrm{cc}$, the color was white. The size of the tumor shown in Figure 4. The results of microscopic examination showed a muscle tissue, fibrous tissue, and bone tissue. There was no malignancy. The result of the examination concluded as a neurofibroma pattern. The results of microscopic examination shown in figure 3.The patient condition at 24 hours after the surgery was quite good, there was no postoperative pain. The patient was treated with Fixed Dose Combination of Antituberculosis Drugs first category, 2 tablets every Tuesday, Thursday, and Saturday (continuation phase). At the first month after the surgery, the patient condition was very good. But the patient still could not move both of her legs and could not urinate. The patient was used Thoracic
Lumbosacral Ortheses (TLSO) that was given from Physical Medicine and Rehabilitation Department. The patient still treated with Fixed Dose Combination of Antituberculosis Drugs first category, 2 tablets every Tuesday, Thursday, and Saturday (continuation phase).

\section{Discussion}

In this paper, a case of 24-years-old female was reported, diagnosed with Meningitis TB on Fixed Dose Combination(FDC) of first category Antituberculosis Drugs at fourth months, militay TB on first category FDC of Antituberculosis at fourth months, and thoracic vertebrae tumor at T11-12 level post laminectomy and tumor excision surgery with neurofibroma patterns. One and a half months before admitted to the hospital, the patient was diagnosed with meningitis $\mathrm{TB}$, miliary $\mathrm{TB}$, and thoracic vertebrae tumor at T11-12 level from a private hospital in Malang. The patient was treated with first category FDC Antituberculosis for four months and was given intramuscular streptomycin for the first month of treatment. The clinical outcome evaluated after the treatment showed an improvement. 
The patient's level of consciousness was very good and the sputum examination was negative at the end of second month intensive phase treatment. Diagnosis was made based on the history taking, physical examination, and laboratory and imaging examination. From the history taking, the patient complaining of could

- Back pain, radiating to another parts of the body, persistent, and progressive

- Loss of sensation or muscle weakness, especially at the upper and lower extremities

- Difficulty of walking, sometimes the patients fell

- Decreased sensitivity to pain, hot, or cold

- Loss of micturition function and defecation

- Paralysis with varied degree and varied parts of the body, depend on the compressed nerve parts.

From the physical examination, there was atrophy at the lower extremities, especially Gastrocnemius muscle. There was also loss of motoric power at the both of lower extremities. There was hypesthesia at thoracic vertebrae T11 level. There was also urine retention ${ }^{10}$. The CXR examination showed military infiltrate pattern at the whole lung field. not move both of her legs and could not urinate since February 2013. According to the literature, weakness of the lower extremities and loss of micturition function was some symptoms of spinal tumor, specifically neurofibroma. According to the literature, the symptoms of spinal tumor consists of ${ }^{10}$ : According to the literature, Miliary TB shown a military nodul pattern $(<2 \mathrm{~mm})$. At the end of second month of intensive phase therapy, there was improvement in the chest $\mathrm{x}$-ray results, with decrease of miliary infiltrate.

From the CT Scan examination in this patient, at first showed no deformities. But apparently, there was meningoencephalitis pattern. According to the literature, Head CT scan on meningitis TB consist of normal, diffuse edema, inflammation, obstructive hydrocephalus, infarct, and tuberculoma. Moreover, granuloma that was formed can be merged and formed tuberculoma that causing focal neurological deficit depend on the location ${ }^{10}$. The thoracolumbal MRI results of this patient showed meningioma patterns at T11-12 level. After the review at the Saiful Anwar General Hospital, there was intramedullar lesion at T11-12 level with 
myelum edema at the surrounding,

The spirometry results showed that there was moderate restriction and no obstruction. Miliary lesion at the lung can cause restriction and diffusion abnormalities and at the extreme case can cause Adult Respiratory Distress Syndrome (ARDS) ${ }^{5}$.

Fiber optic bronchoscopy examination in this patient showed a normal result (class II). According to the literature, cumulative diagnosis of varied bronchoscopy specimens from culture and smear examination is $46,8 \% \%^{5}$. According to the literature, neurofibroma classified as a intradural extramedullary spinal tumor ${ }^{11}$. At the surgery, there was intradural intramedullary spinal tumor. Then a review of histopathology examination showed no malignancy in bone tissue, striated muscle tissue, and connective tissue.

In this patient, surgery was indicated because of the neurological deficit in the form of paralysis at the lower extremities and autonomic disorder in the form of urine retention. Surgery performed was laminectomy and tumor excision. Based on the literature, therapy for spinal tumor is tumor excision surgery ${ }^{12}$.

This patient was used TLSO. The use of TLSO is recommended in patients suspected with intramedullary abscess. with lesions involving more than two vertebrae $^{12}$. In this patient, TLSO was used which was adjusted to the level of the lesion and used until the fusion become consolidated. Evaluation of the patient after the surgery and after discharged from hospital was in a good condition. But the patient still could not move both of her legs and could not urinate until three months after the surgery. According to the references, because of neurofibroma tend to cover the nerve fibers, these tumors usually cannot be dissected from the main nerve ${ }^{13}$.

\section{Conclusions}

Case of a 24-year-old female diagnosed with meningitis TB; miliary TB; thoracic vertebrae tumor at T11-12 level with neurofibroma patterns was reported. The patient admitted to the hospital complaining of could not move both of her legs and could not urinate. One month before admission, she was diagnosed with meningitis TB ; miliary TB ; meningioma at thoracic vertebrae T11-12 based on physical examination, laboratory examination, CXR, Head CT without contrast, and thoracolumbal MRI. When admitted to the hospital, the patient already treated with FDC of 
Antituberculosis Drugs first category for one and a half month from Turen Primary Healthcare. Then the patient underwent bronchoscopy examination. The result of the anatomical pathology examination showed class two. Then the patient underwent a laminectomy surgery and tumor excision at thoracic vertebrae T11-12. The result of postoperative Anatomical Pathology

\section{References}

1. Elias J, Fishman A, Grippi M, Pack A, Senior R. 2008. Pulmonary Diseases and Disorders,4th Ed., Mc GrawHill Medical.

2. Brodie D, Schluger NW: The diagnosis of tuberculosis. Clin Chest Med 2005; 26:247271.

3. Ghanashyam B. Tuberculosis diagnostics: innovating to make an impact. Expert Rev Anti Infect Ther. 2011;9:381-384.

4. Lange C, Mori T. Advances in the diagnosis of tuberculosis. Respirology. 2010;15:220 240

5. Ray S, Talukdar A, Kundu S, Khanra D, Santhalia N. Diagnosis and management of miliary tuberculosis: current state and future perspectives. Dove Medical Press Ltd. Therapeutics and Clinical Risk Management. India. 2013:9 9-26

6. World Health Organization. WHO Report: Global Tuberculosis Control. Geneva: World Health Organization; 2011

7. Sharma SK, Mohan A. Disseminated and miliary tuberculosis. In: Sharma SK, Mohan A, editors. Tuberculosis, 2nd ed. New Delhi: Jaypee Brothers; 2009:493-518.

8. Fanning A: Tuberculosis 6: Extrapulmonary disease. CMAJ 160:1597-1603, 1999

9. Weissleder R, Wittenberg J, M.D. MG et-al. Primer of Diagnostic Imaging, Expert Consult- Online and Print. Mosby. (2011)

10. Murray RA, Mansoor N, Harbacheuski R, et al. Bacillus Calmette Guerin vaccination of human newborns induces a specific, functional $\mathrm{CD} 8+\mathrm{T}$ cell response. $J$ Immunol. 2006;177:5647-5651. examination showed a neurofibroma pattern. After surgery, the Physical Medicine and Rehabilitation Department placed TLSO to the patient. Postoperative evaluation up to three months showed that the patient's general condition was quite good but still cannot move both of her legs and cannot urinate.

11. Donthineni R. Diagnosis and staging of spine tumors. Orthopedic Clinics of North America. 2009;40:1.

12. Nataprawira H.M., Rahim A.H., Dewi M.M., Ismail Y. 2010. Comparation Between Operative and Conservative Therapy in Spondylitis Tuberculosis. Maj Kedokt Indon 60;7: 318-23.

13. Brant WE, Helms CA. Fundamentals of Diagnostic Radiology. Lippincott Williams \& Wilkins. (2007) ISBN:0781761352 